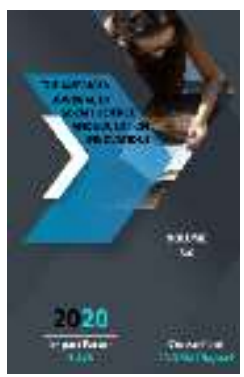

\title{
Physical Training Of Young Athlietes And Its Importance
}

\author{
Kurbanov Shuhrat Kuldoshovich \\ Techer Of "Interfaculty Physical Culture And Sports" Department Of Bukhara State \\ University, Faculty Of Physical Culture, Uzbekistan
}

\begin{abstract}
Journal Website: http://usajournalshub.c om/index,php/tajssei

Copyright: Original content from this work may be used under the terms of the creative commons attributes 4.0 licence.
\end{abstract}

\section{ABSTRACT}

The article shows now increase the physical activity of young athletes and ways to train young athletes through the amount of workload applied to them.

\section{KEYWORDS}

Education, general physical training, special physical training, physical ability, physical quality.

\section{INTRODUCTION}

Physical training of young athletes is one of the most important components of sports training and is understood as a process aimed at comprehensive development of the body, strengthening health, improving physical abilities and creating a solid functional base for all other types of training.

High demands are placed on modern exercise.
This can be explained by management factors:

1. The study of achievements in sports always meets the requirements of a new stage in the development of physical activity from the athlete:

2. A prerequisite for managing a high level of physical training and competition loads. 
Depending on the nature and direction of the effect of the means used, the physical fitness of young athletes is studied in groups of general physical training (GPT), auxiliary and special physical training (GPT).

The general physical fitness (SPT) of a young athlete is the foundation, the necessary foundation, to achieve high results. It is aimed at solving the following tasks.

1. Improving the functional capacity of the body of young athletes

2. Physical qualities Development of strength, speed, endurance, agility and flexibility:

3. Overcoming deficiencies in the physical development of young athletes.

Auxiliary physical training of young athletes is aimed at creating a functional basis for effective activities aimed at the development of special physical abilities. It has a special direction and is aimed at solving the following tasks:

1. Development of functional abilities of young athletes, which are reflected in the movement activities specific to the chosen sport.

2. Improving the body's ability to withstand high levels of special loads.

3. Increasing the intensity of recovery processes.

Special training of young athletes (GPT) is carried out regardless of the sport in which they meet the requirements for participation in competitive activities in the chosen sport.
Solves the task of managing the special performance of young athletes.

- Improvement of mandatory treatment specific to the chosen sport;

- Deepening and development of motor skills necessary for successful technical and tactical improvement of the chosen sport;

- Selective development of individual muscle groups that are more involved in performing specialized exercises;

It is aimed at developing the most important movement qualities in the system of GPT movement skills of young athletes. To do this, competitive exercises conducted by the main management of special physical training are used with various complicating elements that affect the body of the athlete.

All types of physical training have certain similarities. Physical training of young athletes is closely linked with sports specialization. Inadequate assessment of any type of physical fitness during exercise will eventually hinder the development of sports skills. In the training of young athletes, the tasks set in the ratio of GPT and SPT, the age and qualifications of athletes, their individual characteristics, stages and periods of the training process, change the current state of the body. As the skill of the athlete increases, the contribution of MJT tools increases and the volume of SPT tools decreases accordingly.

\section{MATERIALS AND METHODS}

The level of physical development of young athletes during training. 
(Table 1)

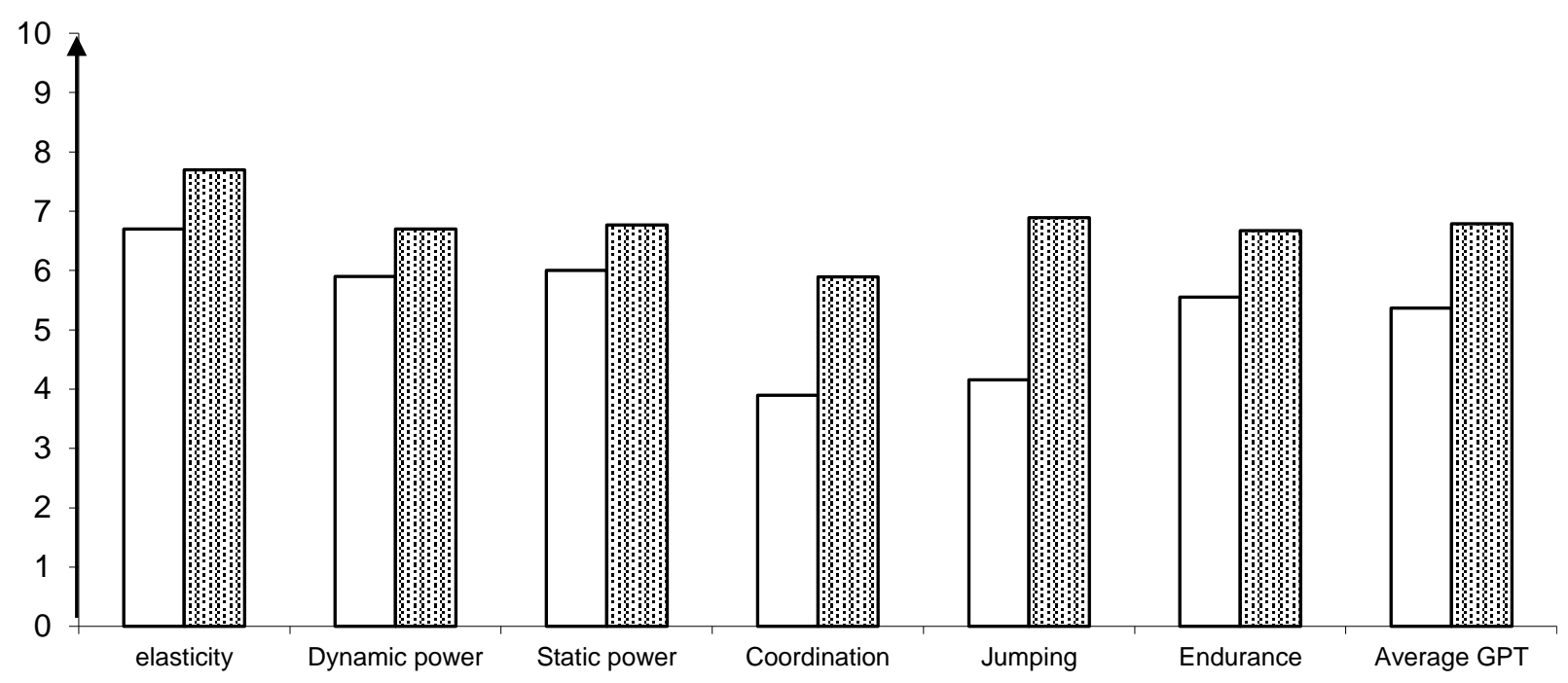

$\square$ Pre-workout growth rate

In addition: The formation of the physical culture of young athletes also remains an important factor. The process of shaping the physical culture of such young athletes not only assimilates the movements of the practitioners and the knowledge associated with them, but also develops their own physical activities. Currently, "physical activity" and "physical qualities" are used to describe the ability of athletes to move. Although these concepts are similar in some ways, but not the same. Physical control is a complex of psychophysiological and morphological actions that meet the requirements of a young athlete and ensure their implementation. In physical education and sports, the terms "strong," "fast," "agile," and "flexible" are reflected in the quality of athletes 'performance.
๑ Growth rate during training.

It is now accepted to distinguish five basic types of physical abilities: strength, speed and coordination skills, endurance and flexibility. Each of them manifests itself in different forms in different types of movement activities.

Now there are also basic laws of development of physical abilities.

1. Movement is a leading factor of physical abilities

2. Dependence of skill development on the mode of movement activity

3. Stages of development of physical abilities

4. Uneven and heterochronous development of abilities (belonging to different times)

5. Reversibility of ability indicators

6. Transfer of physical abilities

7. Interrelation and unity of motor skills and physical abilities 
In doing so, there is no change that affects the performance of young athletes, depending on their mastery of this or that movement in the belt they are considering. To do this, the person who conducts the pedagogical process of physical education must build it based not only on the principles of education and upbringing, but also on the principles of development of physical activity. At the same time, it is necessary to accept that all sports competitions in physical education reflect the same requirements: in them, any pedagogical process must be built on the basis of awareness, activism and other principles. However, the clear implementation of these principles must be consistent with the tasks at hand.

\section{CONCLUSION}

Thus, the actual values of the maximum load can be determined only in relation to the specific physical condition of the trainees.

Of course, in the development of physical abilities, the maximum load should be applied when the trainees have the appropriate training, taking into account their age, individual characteristics, as well as the specifics of the load, in accordance with other principles. The magnitude of the physical load is characterized by its volume and intensity. Accordingly, it is possible to clearly distribute the workload.

\section{REFERENCES}

1. Law on Physical Culture and Sports, June 27, 2000 Folk word pages 1-2.

2. Vardiashvili.I.R "Scientific cognitive activity of students". Karshi. Nasaf Publishing House, 2006.

3. Krimov.FA "Scientific research in the field of sports”. T. "Zarqalam” publisher. 2004
4. Gomelskiy.A.Ya. Tactics of basketball. M: FIS, 1966.

5. Ganchorova O.V. "Development of physical abilities of young athletes", 2005

6. Usmonhojaev TS, Khojaev F. 1001 game T. Publishing house "Ibn Sino", 1990

7. S.S.Abdueva, Sh.Khurbonov,N.Sabirova. Evolution of physical performance and techniques of handball girls aged 11-12. International Journal of Advanced Research in Science, Engineering and Technology (IJARSET). 2019 december

8. S.S.Abdueva. Activities that increase children's interest in the sport of handball. Innovatsionnoe razvitie nauki I obrozovanie mejdunarodnaya nauchnoprakticheskaya konferensiya 2020

9. S.S.Abdueva,Sh.Kadirov,M.Fatullaeva,Sh.K hurbonov. Using of innovation terms in physical education and sport lessons and their social and educational features. Journal of Critical Reviews ISSN-2394-5125 Vol 7,Issue 6,2020 